\title{
ANTI-TRYPTIC ACTIVITY OF SYNOVIAL FLUID IN PATIENTS WITH VARIOUS TYPES OF ARTHRITIS ${ }^{1}$
}

\author{
By WILLIAM F. HOLMES, JR., CHESTER S. KEEFER and WALTER K. MYERS \\ (From the Thorndike Memorial Laboratory, Second and Fourth Medical Service (Harvard), \\ Boston City Hospital and the Department of Medicine, Harvard Medical School, Boston)
}

(Received for publication September 18, 1934)

For many years it has been known that blood plasma is capable of inhibiting the action of proteolytic ferments, and especially trypsin. The presence of this property of blood plasma probably plays a part in limiting the damage to tissue by inflammatory exudates containing large numbers of polymorphonuclear leukocytes. In view of the fact that blood plasma possesses anti-tryptic properties, it was of interest to us to determine whether or not similar properties could be detected in synovial fluid from patients with various types of arthritis. Further, we were interested in knowing whether these qualities of the synovial fluid fluctuated in various cases. In all, we studied sixty-five samples of synovial fluid from fortyfive cases of arthritis, including thirty cases of gonococcal arthritis, five cases of rheumatic fever, six cases of rheumatoid arthritis and four cases in which there was an accumulation of synovial fluid into a joint following injury. Inasmuch as the procedures differed with various experiments, the methods will be described with the individual experiments.

\section{The demonstration of anti-tryptic substances in synovial fluid}

\section{Presentation of data:}

The first set of experiments was designed to determine whether or not synovial fluid would inhibit the action of trypsin when it was mixed with casein. One cubic centimeter of 1 per cent trypsin solution was mixed with 5 cc. of 1 per cent solution of casein, made up to a volume of $10 \mathrm{cc}$. and placed in the incubator at $37^{\circ} \mathrm{C}$. for twentyfour hours. At the same time, similar mixtures containing synovial fluid, $0.1,0.2,0.4$ and $0.8 \mathrm{cc}$, respectively, were incubated for twenty-four hours. At the end of this period, nonprotein

1 This investigation was aided in part by a grant from the Proctor Fund of the Harvard Medical School for the Study of Chronic Diseases. nitrogen determinations were made on all of the mixtures to determine the amount of protein digested. Synovial fluid alone was incubated for twenty-four hours and the nonprotein nitrogen content of this fluid together with that of the trypsin-casein mixture without synovial fluid served as controls. In all, thirty-two synovial fluids were examined in this way. In sixteen the inhibiting power of $1 \mathrm{cc}$. of synovial fluid was determined whereas in the remaining sixteen varying amounts of synovial fluid, from 0.1 to 0.8 cc., were studied. A typical example of the experiment is shown in Table $I$, and the results obtained in the thirty-two cases are charted in

TABLE I

Example of experiment showing the effect of adding varying quantities of synovial fluid to a mixture of trypsin and casein.

\begin{tabular}{|c|c|c|c|c|c|c|c|c|}
\hline Tube number. & 1 & 2 & 3 & 3 & 4 & 5 & 7 & 8 \\
\hline $\begin{array}{c}\text { Trypsin } 1 \text { per cent } \\
\text { solution, } c c . \ldots \ldots \ldots \\
\text { Casein } 1 \text { per cent so- } \\
\text { lution, } c c . \ldots \ldots \ldots \\
\text { Synovial fluid, } c c . \ldots \\
\text { Saline solution, } c c . . \\
\text { Nonprotein nitrogen, } \\
\text { mgm. per } 100 c c . .\end{array}$ & $\begin{array}{r}1 \\
5 \\
0 \\
4 \\
50\end{array}$ & $\begin{array}{l}0 \\
0 \\
2 \\
8 \\
8.1\end{array}$ & $\begin{array}{l}1 \\
5 \\
0.1 \\
3.9 \\
65\end{array}$ & $\begin{array}{l}1 \\
5 \\
0.2 \\
3.8 \\
65\end{array}$ & \begin{tabular}{|l|}
1 \\
5 \\
0.4 \\
3.7 \\
82
\end{tabular} & \begin{tabular}{|l|}
1 \\
5 \\
0.8 \\
3.6 \\
92
\end{tabular} & $\begin{array}{r}1 \\
0 \\
0 \\
9 \\
15\end{array}$ & $\begin{array}{l}5 \\
0 \\
4 \\
0\end{array}$ \\
\hline
\end{tabular}

Figure 1. From this figure one may observe that some samples of synovial fluid were capable of inhibiting the action of trypsin on casein solution and others were not. It is seen in individual cases that when synovial fluid inhibited the digestion of casein by trypsin, the larger the amount of synovial fluid used the greater the inhibition. This was probably due to the addition of larger amounts of anti-tryptic substances with increasing amounts of synovial fluid. When there was little or no inhibiting effect present, the amount of digestion increased when large amounts of synovial fluid were added to the mixture. This was prob- 


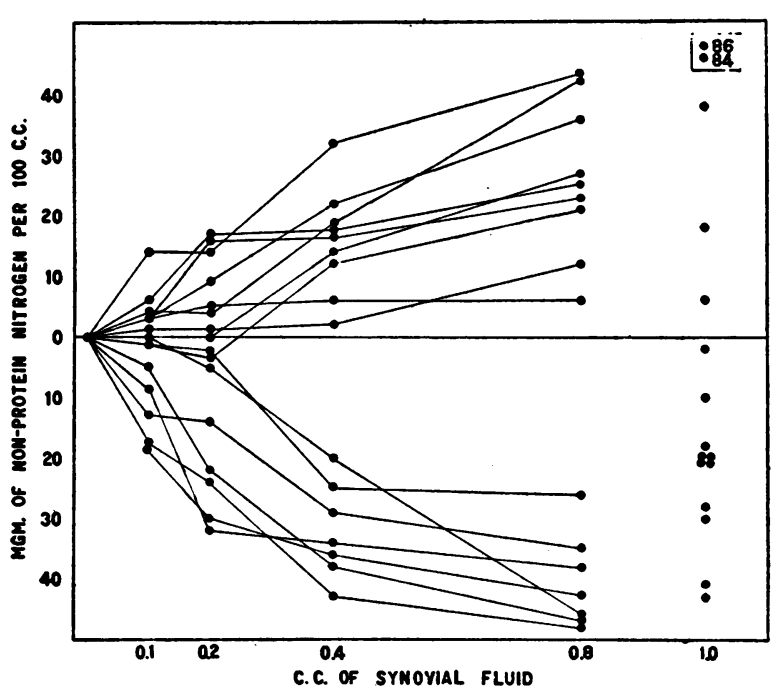

Fig. 1. The Difference in Nonprotein Nitrogen Liberated after Adding Varying Amounts of Several Synovial Flums to Control Trypsin-Casein Mrxtures.

The zero line represents the nonprotein nitrogen found in the control trypsin-casein mixtures. Each line represents a particular synovial fluid. The dots at the extreme right of the chart indicate the difference in nonprotein nitrogen liberated above or below that of control trypsin-casein mixtures, where $1 \mathrm{cc}$. of each of sixteen synovial fluids was added.

ably due in part to the increased amount of protein substrate contained in the synovial fluid.

From these observations, one may conclude that in some samples of synovial fluid there are substances which are capable of inhibiting the action of tryptic ferments when added to a mixture of trypsin and casein; in others they can not be demonstrated. In order to determine whether or not these properties could be removed by the addition of chloroform to synovial fluid, as is the case with blood plasma (1), ten samples of synovial fluid were studied before and after they had been mixed with chloroform. One cubic centimeter of synovial fluid was mixed with $1 \mathrm{cc}$. of 1 per cent solution of trypsin and $5 \mathrm{cc}$. of 1 per cent casein solution, made up to a volume of $10 \mathrm{cc}$. with normal salt solution and incubated for twenty-four hours at $37^{\circ} \mathrm{C}$. At the same time, a similar amount of synovial fluid, which had been mixed with equal amounts of chloroform and incubated for two hours at $37^{\circ} \mathrm{C}$. and then separated, was studied in like manner. The trypsin-casein mixture without synovial fluid was incubated as a control. In addition, the nonprotein nitrogen of two samples of synovial fluid alone was determined after incubation for twentyfour hours. One sample was mixed with chloroform and the other was not. A summary of these experiments appears in Figure 2. It is plain that when chloroform was added to synovial fluid anti-tryptic substances were removed inasmuch as the digestion of the protein was always greater with synovial fluid which had been treated with chloroform. A typical experiment is shown in Table II.

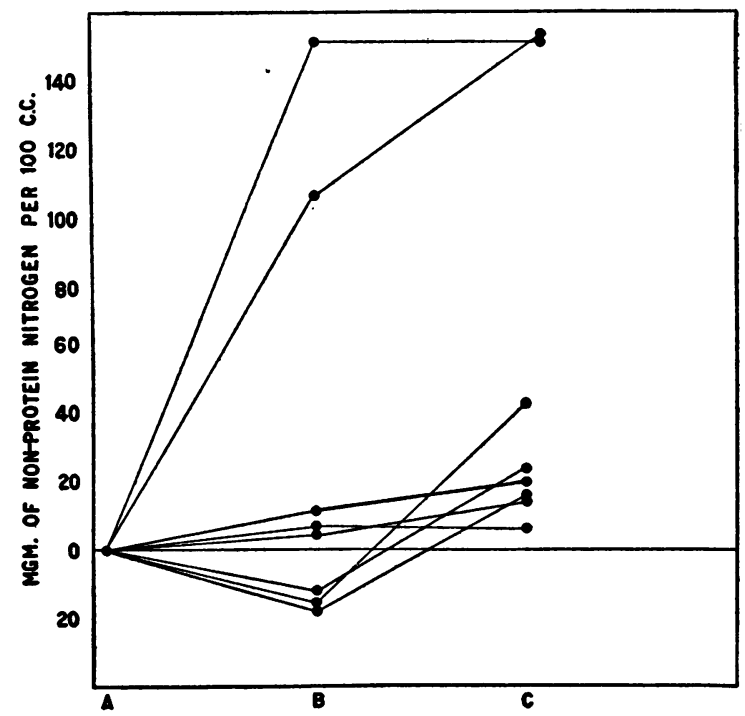

Fig. 2. The Difference in Nonprotein Nitrogen Liberated after Adping to Control Trypsin-Casein Mixtures 1 cc. of Several Synovial Fluids $(B)$ or 1 cc. of These Same Synovial Flums after They Had Been Extracted with Chloroform ( $C$ ).

The zero line represents the nonprotein nitrogen found in the control trypsin-casein mixtures.

In another series of experiments, the ability of trypsin to digest the protein of the synovial fluid without the addition of casein was studied. In this way it was also possible to determine differences in the anti-tryptic activity of synovial fluid. One cubic centimeter of trypsin was added to 2 cc. of synovial fluid and made up to a volume of $10 \mathrm{cc}$. with sterile normal salt solution and incubated at $37^{\circ} \mathrm{C}$. for twenty-four hours; then nonprotein nitrogen determinations were made to discover how much protein had been digested. The nonprotein nitrogen content of synovial fluid alone and of the trypsin alone served as controls. 
TABLE II

Example of experiment showing the effect of synovial fluid on the digestion of a trypsin-casein mixture before and after removing the anti-tryptic substances from the synovial fluid.

\begin{tabular}{|c|c|c|c|c|c|}
\hline & Control & & & Control & Control \\
\hline Tube number. . & 1 & 2 & 3 & 4 & 5 \\
\hline 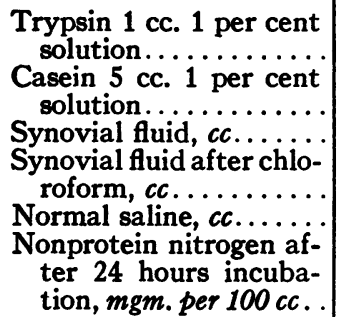 & $\begin{array}{c}+ \\
+ \\
0 \\
0 \\
4 \\
43.5\end{array}$ & $\begin{array}{c}+ \\
+ \\
1 \\
0 \\
3 \\
\\
29.5\end{array}$ & $\begin{array}{c}+ \\
+ \\
0 \\
1 \\
3 \\
67.5\end{array}$ & $\begin{array}{l}0 \\
0 \\
2 \\
0 \\
8 \\
8.0\end{array}$ & $\begin{array}{l}0 \\
0 \\
0 \\
2 \\
8\end{array}$ \\
\hline
\end{tabular}

At the same time, synovial fluid which had been treated with chloroform to remove the anti-tryptic substances was studied in a similar fashion. An example of an experiment and the results are shown in Table III and Figure 3.

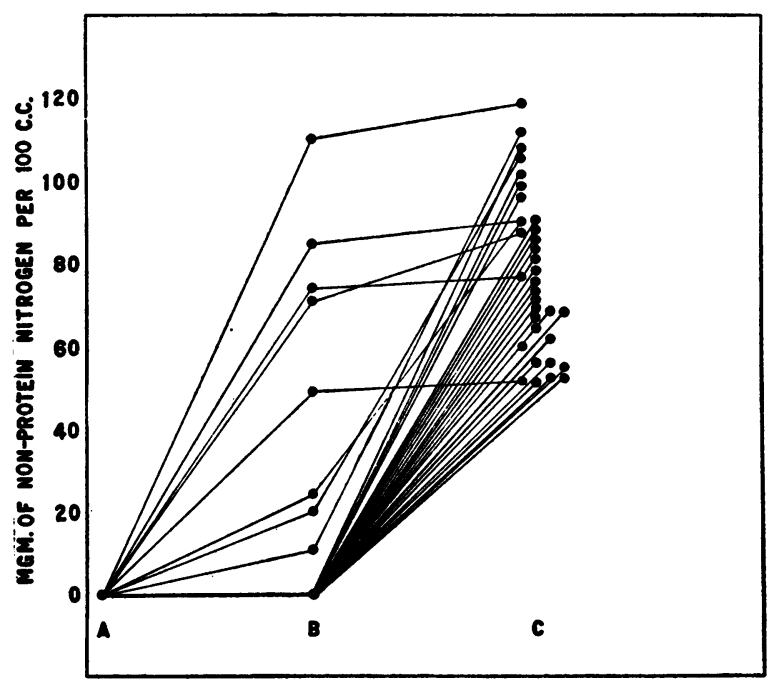

Fig. 3. The Digestion in Mixtures of Trypsin with Synovial Fluids $(B)$ and with the Same Synovial Fluids after They Had Been Extracted with Chloroform $(C)$.

The zero line represents the sum of the nonprotein nitrogen in the synovial fluid alone and in the trypsin alone.

Twenty-six of the thirty-four samples of synovial fluid completely inhibited the digestive action of $1 \mathrm{cc}$. of 1 per cent trypsin. In the other eight, some digestion took place indicating that
TABLE III

Example of experiment to determine the anti-tryptic action of synovial fluid when the protein of the synovial fluid was used as a substrate.

\begin{tabular}{|c|c|c|c|c|c|}
\hline Tube number. & 1 & 2 & 3 & 4 & 5 \\
\hline 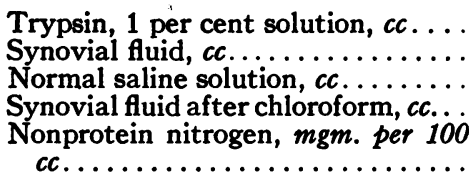 & $\begin{array}{r}1 \\
2 \\
7 \\
0 \\
23\end{array}$ & $\begin{array}{r}1 \\
0 \\
9 \\
0 \\
15\end{array}$ & $\begin{array}{l}0 \\
2 \\
8 \\
0 \\
8\end{array}$ & $\begin{array}{r}1 \\
0 \\
7 \\
2 \\
83\end{array}$ & $\begin{array}{l}0 \\
0 \\
8 \\
2\end{array}$ \\
\hline
\end{tabular}

the anti-tryptic activity of these fluids was less than the others. When chloroform was added to the fluid to remove the anti-ferment substances, then tryptic digestion was always manifest. The difference in the degree of digestion in the different samples of synovial fluid after they had been treated with chloroform was undoubtedly dependent upon the fact that both the substrate and the free ferment varied in the different samples.

From the above observations, there was no doubt that some samples of synovial fluid contain substances that will inhibit the action of trypsin when it is incubated with casein or the protein of synovial fluid. It was also plain that the antitryptic substances could be removed from synovial fluid with chloroform.

We then proceeded to study the various factors that were responsible for the variations in the anti-tryptic activity of the synovial fluid.

Relation of the total number of cells in the synovial fluid and the anti-tryptic content

Since polymorphonuclear leukocytes contain tryptic ferments and they were present in varying numbers in the different samples of fluid, it was of interest to determine whether there was any correlation between the number of cells in the synovial fluid and its anti-tryptic power. The results of such a study, based on the thirty-two cases recorded in Figure 1, are summarized in Table IV.

From this table, it is seen that, on the whole, the higher the polymorphonuclear cell count the greater the ferment action. In other words, the synovial fluids showing anti-tryptic activity were those with lower cell counts. This was also true of the cases recorded in Figure 2. In six of the 
TABLE IV

Correlation of anti-tryptic potency of synovial fluid and polymorphonuclear cell counts in 32 cases

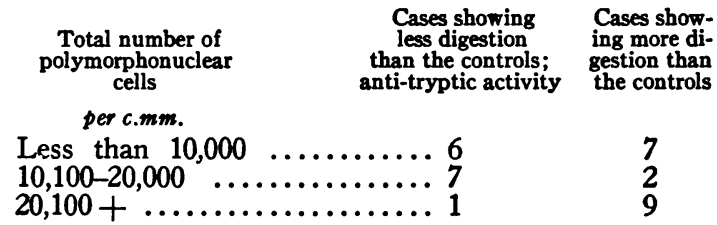

eight cases in which the fluid showed less antitryptic power than the others, the cell count was over 25,000 per c.mm.; whereas of the twenty-six fluids showing higher anti-tryptic power, only six had cell counts above 20,000 per c.mm.

These observations suggested that the diminished anti-tryptic action of some of the fluids was due to the presence of an excess amount of proteolytic ferment derived from the polymorphonuclear leukocytes. Before accepting this conclusion, however, it was necessary to determine three things: (1) the effect of adding increasing amounts of trypsin to constant amounts of protein; (2) the effect of incubating casein with synovial fluids containing varying numbers of leukocytes; and (3) the effect of increasing the amount of protein substrate when the ferment was kept constant.

\section{Effect of increasing the amount of ferment, keep-} ing the amount of synovial fluid constant

To determine the effect of increasing the amount of ferment added to a synovial fluid that showed anti-tryptic activity, varying amounts of a 1 per cent solution of trypsin were added to $0.5 \mathrm{cc}$. of synovial fluid, and the total volume was made up to $10 \mathrm{cc}$. and incubated at $37^{\circ} \mathrm{C}$. for twenty-four hours. As a control the same amounts of ferment were added to synovial fluid after it had been treated with chloroform to remove the anti-tryptic substances. The results of these two experiments were compared with those that were obtained when increasing amounts of trypsin were added to a casein solution. The curves are charted in Figure 4. There was no digestion of the synovial fluid protein with $3 \mathrm{cc}$. or less of trypsin; however, the digestion was obvious and maximal with $5 \mathrm{cc}$. (Curve $A$ ). When the anti-tryptic substances were removed with chloroform, the digestion was maximal with 3 cc. of trypsin. Moreover, when a substrate such as casein was kept constant and the ferment increased, then digestion increased with increasing amounts of ferment (Curve $C$ ). From these experiments it appears that anti-tryptic activity of the synovial fluid may be overcome by an excess of ferment.

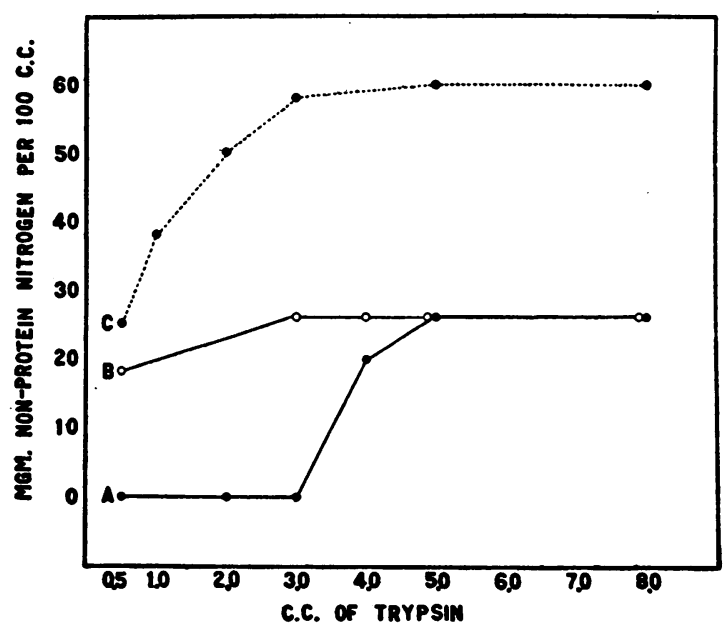

Fig. 4. Diagram Illustrating the Digestion of Protein with Increasing Amounts of Ferment, Added to a Constant Amount of Substrates.

$A$. Substrate: synovial fluid.

$B$. Substrate: synovial fluid after the anti-tryptic substances had been removed by chloroform.

C. Substrate: Casein solution.

Effect of incubating casein with synovial fluids containing varying numbers of leukocytes

It was necessary, then, to determine the effect of adding samples of synovial fluid containing varying numbers of leukocytes to a solution of casein. Two cubic centimeters of synovial fluid were mixed with $5 \mathrm{cc}$. of 1 per cent solution of casein and made up to a volume of $10 \mathrm{cc}$. with normal salt solution. This was incubated at $37^{\circ}$ C. for twenty-four hours under conditions insuring sterility. As controls, synovial fluid alone and casein solution alone were incubated at the same time. To be certain that the ferment in the synovial fluid would not be inhibited by the antitryptic substances these in a second series were removed with chloroform. In these preparations synovial fluid which had been treated with chloroform was added to the casein solution and studied in the same way. The results of these experiments are summarized in Table $\mathrm{V}$. 
TABLE V

Results of incubating casein and synovial fluid containing varying numbers of cells

\begin{tabular}{|c|c|c|c|c|c|}
\hline Case & $\begin{array}{l}\text { Synovial fluid. } \\
\text { Nonprotein } \\
\text { nitrogen }\end{array}$ & $\begin{array}{l}\text { Casein solution } \\
1 \text { per cent. } \\
\text { Nonprotein nitrogen }\end{array}$ & $\begin{array}{l}\text { Synovial fluid } 2 \mathrm{cc} \text {. and } \\
1 \text { per cent casein solution. } \\
\text { Nonprotein nitrogen }\end{array}$ & $\begin{array}{l}\text { Synovial fluid } 2 \text { cc. after } \\
\text { treatment with chloroform } \\
\text { and } 1 \text { per cent } \\
\text { casein solution. } \\
\text { Nonprotein nitrogen }\end{array}$ & Total cell count \\
\hline $\begin{array}{l}1 \\
2 \\
3 \\
4 \\
5\end{array}$ & $\begin{array}{c}\text { mgm. per } 100 \text { cc. } \\
7.1 \\
6.8 \\
7.8 \\
7.1 \\
10.0\end{array}$ & $\begin{array}{c}\text { mgm. per } 100 c c . \\
0 \\
0 \\
0 \\
0 \\
0\end{array}$ & $\begin{array}{c}\text { mgm. per } 100 \text { cc. } \\
23.4 \\
18.7 \\
15.0 \\
21.0 \\
32.9\end{array}$ & $\begin{array}{c}\text { mgm. per } 100 \text { cc. } \\
22.2 \\
15.7 \\
12.5 \\
20.0 \\
29.4\end{array}$ & $\begin{array}{c}\text { per c. } m m \text {. } \\
40,000 \\
26,000 \\
20,000 \\
24,000 \\
22,000\end{array}$ \\
\hline $\begin{array}{r}6 \\
7 \\
8 \\
9 \\
10 \\
11 \\
12\end{array}$ & $\begin{array}{r}6.8 \\
10.0 \\
7.7 \\
7.1 \\
6.0 \\
6.2 \\
6.9\end{array}$ & $\begin{array}{l}0 \\
0 \\
0 \\
0 \\
0 \\
0 \\
0\end{array}$ & $\begin{array}{r}9.1 \\
13.4 \\
8.6 \\
10.0 \\
8.3 \\
6.5 \\
9.3\end{array}$ & $\begin{array}{r}8.8 \\
13.0 \\
8.6 \\
10.0 \\
8.0 \\
9.0 \\
9.0\end{array}$ & $\begin{array}{r}10,000 \\
2,500 \\
7,500 \\
12,000 \\
12,000 \\
10,500 \\
12,000\end{array}$ \\
\hline
\end{tabular}

It is manifest that the samples of synovial fluid placed in the upper part of Table $\mathrm{V}$ were capable of digesting casein. In the others, the evidence that the digestion took place was slight or lacking. When the results of digestion were correlated with the total cell count it was found that the cases showing digestion of the casein were those with higher total cell counts, whereas those showing little or no digestion contained fewer cells. It would appear, then, that the presence of large numbers of cells in synovial fluid increases the content of proteolytic ferment and in that way is responsible for increased digestion of the protein. That the lack of digestion of the protein in some samples of synovial fluid was not due entirely to the presence of excess amounts of anti-tryptic substances is borne out by the very slight change in digestion after removing them with chloroform.

\section{Effect of increasing the protein substrate with a constant amount of ferment}

In the experiment in which increasing amounts of synovial fluid were added to trypsin and casein, the protein substrate was obviously increased (Figure 1). It was necessary, therefore, to study the effect of adding increasing amounts of synovial fluid to a constant amount of ferment. One cubic centimeter of a 1 per cent solution of trypsin was added to varying amounts of synovial fluid and incubated for twenty-four hours. The same procedure was carried out with increasing amounts of synovial fluid which had been previously incubated with chloroform to remove the anti-tryptic substances. The results are charted in Figure 5. When the anti-tryptic substances were removed from the synovial fluid with

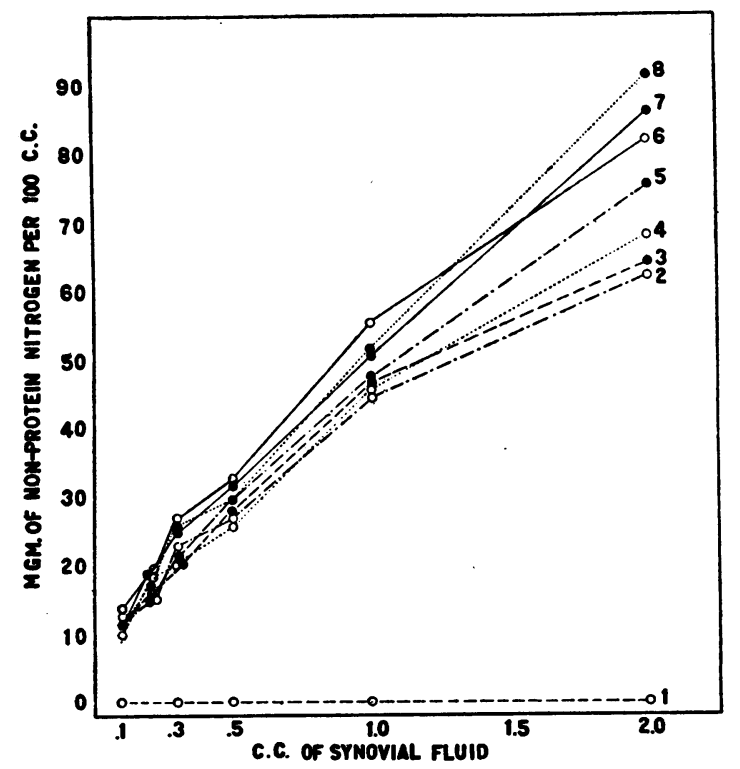

Fig. 5. Diagram Illustrating the Effect of Digesting Increasing Amounts of Synovial Fluid Which Had Been Previously Treated with Chloroform, When the Amount of Trypsin Is Kept ConSTANT.

1. Control observations using the seven samples of synovial fluid without preliminary treatment with chloroform.

2 to 8 . The amount of digestion above the controls after the seven synovial fluids had been treated with chloroform to remove the anti-tryptic substances. 
chloroform there was increased digestion with increasing amounts of synovial fluid. When the anti-tryptic substances were not removed, no digestion of the protein of the synovial fluid was demonstrated. These experiments showed that increasing the amount of synovial fluid was followed by increased digestion of the protein only if the anti-tryptic substances had first been removed.

\section{Comparison of anti-tryptic power of blood plasma and synovial fluid}

In six instances both the blood plasma and synovial fluid from the same patient were studied to compare their anti-tryptic power. The procedure was the same as when the anti-tryptic substances were studied in synovial fluid namely by adding trypsin before and after treatment with chloroform. The results are charted in Figure 6. Both the blood plasma and synovial fluid in $2 \mathrm{cc}$. amounts were capable of completely inhibiting the action of $1 \mathrm{cc}$. of 1 per cent trypsin solution. When chloroform was added to the blood plasma or to the synovial fluid the trypsin-inhibiting sub-

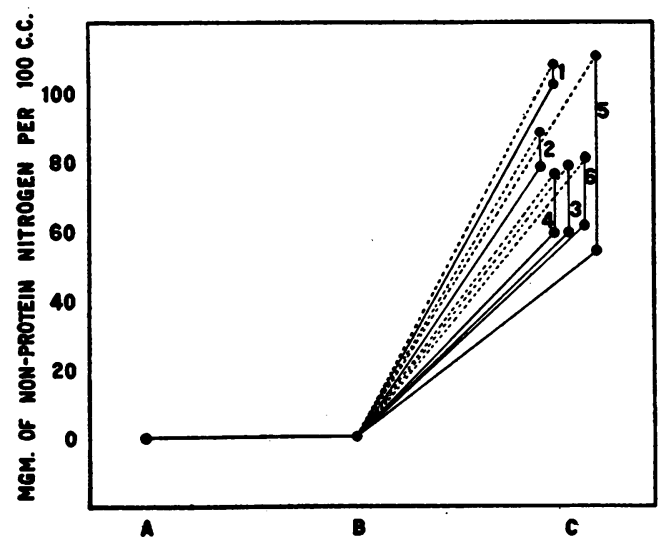

Fig. 6. Diagram Comparing Anti-tryptic Content of Blood Plasma and Synovial Flum from Six PaTIENTS.

$A$. Control for each case. Zero line represents the sum of nonprotein nitrogen in the components of each test measured separately.

$B$. The amount of digestion after incubation of synovial fluid and trypsin.

$C$. The amount of digestion of blood plasma and of synovial fluid after removal of anti-tryptic substances from both with chloroform. Solid lines represent synovial fluid. Interrupted lines represent blood plasma. stances were removed. The digestive products of the chloroform treated blood plasma protein were higher in each instance than those of the chloroform treated synovial fluid from the same subject. This was attributed to the increased amount of protein substrate available in the blood plasma inasmuch as the protein content of the blood plasma was always higher than that of the synovial fluid from the same individual.

It appears to us that the anti-tryptic substances in these cases at least were probably derived from the exudation of blood plasma into the synovial cavity.

\section{DISCUSSION}

The foregoing experiments leave little doubt that synovial fluid from some cases of arthritis is capable of inhibiting tryptic digestion. When the anti-tryptic activity was diminished, it was shown that the presence of a large number of leukocytes which contain tryptic ferments was responsible, in part at least, for this reduced antitryptic activity. This relation was found regardless of the type of arthritis studied. It is not unreasonable to believe that these anti-tryptic substances are derived from the blood plasma, when due consideration is given to the observations comparing the anti-tryptic activity of blood plasma and synovial fluid from the same individuals.

It would appear, then, that when there is an exudation of fluid into the synovial cavities, the synovial fluid partially protects the tissues from the destruction that might follow the ferment action of destroyed leukocytes. The amount of demonstrable anti-ferment present would depend upon the amount in the blood of the individual but restricted by the amount of free proteolytic enzyme in the synovial fluid. It seems likely that the presence of anti-tryptic substances in synovial fluid is one of the protective mechanisms of the body to prevent destruction in arthritis.

\section{SUMMARY AND CONCLUSIONS}

1. Synovial fluid contains substances which are capable of inhibiting tryptic digestion.

2 . When there are a large number of cells, especially polymorphonuclear leukocytes, present in synovial fluid the anti-tryptic power is usually reduced. 
3. The anti-tryptic substances in synovial fluid can be removed by extraction with chloroform.

4. The anti-tryptic substances in the synovial fluid are probably derived from the blood plasma as both plasma and fluid contain comparable amounts of anti-tryptic substances.

5. One of the properties of synovial fluid is to inhibit the tryptic ferments which are present in exudates.
6. The anti-tryptic power of synovial fluid can be counterbalanced by adding an excess of ferment.

\section{BIBLIOGRAPHY}

1. Jobling, J. W., and Petersen, W., The nature of serum antitrypsin. Studies on ferment action XIII. J. Exper. Med., 1914, 19, 459. 